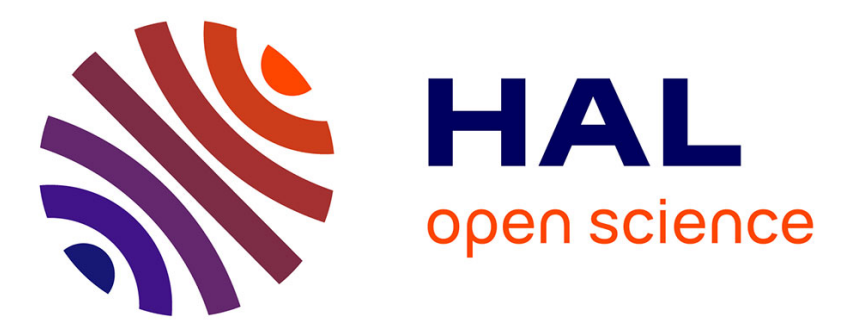

\title{
An inter- and intra-observer study of a classification of RetCam images of retinal haemorrhages in children
} Alan O Mulvihill, Patricia Jones, Anamika Tandon, Brian W Fleck, Robert A Minns

\section{- To cite this version:}

Alan O Mulvihill, Patricia Jones, Anamika Tandon, Brian W Fleck, Robert A Minns. An inter- and intra-observer study of a classification of RetCam images of retinal haemorrhages in children. British Journal of Ophthalmology, 2010, 95 (1), pp.99. 10.1136/bjo.2009.168153 . hal-00557333

\section{HAL Id: hal-00557333 \\ https://hal.science/hal-00557333}

Submitted on 19 Jan 2011

HAL is a multi-disciplinary open access archive for the deposit and dissemination of scientific research documents, whether they are published or not. The documents may come from teaching and research institutions in France or abroad, or from public or private research centers.
L'archive ouverte pluridisciplinaire HAL, est destinée au dépôt et à la diffusion de documents scientifiques de niveau recherche, publiés ou non, émanant des établissements d'enseignement et de recherche français ou étrangers, des laboratoires publics ou privés. 


\title{
An inter- and intra-observer study of a classification of RetCam images of retinal haemorrhages in children
}

Dr Alan O Mulvihill FRCSI, FRCSEd ${ }^{1,2}$, Ms Patricia Jones ${ }^{3}$, Dr Anamika Tandon FRCOphth ${ }^{1,2}$, Dr Brian W Fleck MD, FRCOphth, FRCSEd ${ }^{1,2}$, Prof Robert A Minns MBBS,PhD,FRCP(Ed), FRCPCH ${ }^{2,3}$.

1. Princess Alexandra Eye Pavilion, Chalmers Street, Edinburgh.

2. Royal Hospital for Sick Children, Edinburgh.

3. Child Life and Health, University of Edinburgh.

\author{
Corresponding author: \\ Dr Alan Mulvihill \\ Princess Alexandra Eye Pavilion \\ Chalmers Street \\ Edinburgh \\ EH3 9HA \\ Tel: $\quad 01315361674$ \\ Fax: $\quad 01315361574$ \\ e-mail: alan.mulvihill@googlemail.com
}

Key words; retinal, haemorrhage, children

Word count (excl title page, abstract, references, figures \& tables) $=2716$

The Corresponding Author has the right to grant on behalf of all authors and does grant on behalf of all authors, an exclusive licence (or non-exclusive for government employees) on a worldwide basis to the BMJ Publishing Group Ltd and its Licensees to permit this article (if accepted) to be published in British Journal of Ophthalmology and any other BMJPGL products to exploit all subsidiary rights, as set out in our licence 


\section{Abstract}

Background: There is currently no universally accepted classification of childhood retinal haemorrhages.

Aim: To measure the inter- and intra-observer agreement of clinical classifications of retinal haemorrhages in children.

\section{Methods:}

Four examiners (2 consultant ophthalmologists and 2 other clinicians) were shown 142 retinal haemorrhages on 31 RetCam photographs. The retinal haemorrhages were from children with accidental or abusive head injury, or other encephalopathies, and included retinal haemorrhages of different ages. Specified haemorrhages were initially classified by each examiner according to their clinical understanding. Twenty-six haemorrhages were re-presented to test intra-observer consistency. Examiners then agreed a common description for each haemorrhage type and five categories were described (vitreous, pre-retinal, nerve fibre layer, intra-retinal/sub-retinal, or indeterminate), and the study repeated.

\section{Results:}

There was 'fair agreement' initially (Fleiss' unweighted kappa $=0.219$ ), and with the agreed classification, slight improvement (0.356). Intra-observer agreement marginally improved on re-test. The 2 consultant ophthalmologists showed 'fair' agreement on both occasions (paired kappa statistic). The other rater pair improved from 'fair' to 'substantial' agreement with the new classification.

\section{Conclusions:}

The classification of retinal haemorrhage in children by appearance alone shows only fair agreement between examiners. Clinicians who are not consultant ophthalmologists appear to benefit from the new succinct classification.

(200 words) 


\section{INTRODUCTION}

Retinal haemorrhages are common in infants following abusive head injury and less common following accidental head injury. [1,2] While retinal haemorrhages have previously been described there are however no currently standardised or validated descriptions of childhood retinal haemorrhages. [1-3] There is also an inconsistent approach to the description of childhood retinal haemorrhages in the medical literature. While there is abundant histopathological evidence showing that haemorrhages occur throughout all retinal layers, [4-9] what is lacking is conclusive evidence to show that any clinically recognisable haemorrhage lies at a particular layer of the retina. Large haemorrhages (preretinal or within splits or schisis of the superficial retinal layers) are more easily identified histopathologically but there remains inconsistencies between these pathological findings and the clinical appearance. [9-13] We designed a study to measure the inter- and intra-observer agreement of clinical classifications of RetCam images of retinal haemorrhages in children, where the observers were masked to the likely aetiology of the haemorrhages.

\section{SUBJECTS AND METHODS}

Four examiners were shown 142 haemorrhages on 31 high quality "RetCam" retinal photographs (Clarity Medical Systems, Pleasanton, CA) with a 120 degree "children's" lens. The examiners consisted of two experienced paediatric consultant ophthalmologists, a paediatric ophthalmology fellow and a consultant paediatric neurologist with experience in non-accidental head injury.

The Lothian Regional Ethics Committee approved the use of non-identifiable patient images for these studies. The images included right and left eyes and images of the same eye on different days after admission. The examiners were masked to patient details including the likely aetiologies but each image was identified by laterality (right or left) and the day (from admission) of imaging.

On the advice of a statistician, the retinal images/haemorrhages chosen included a wide range of appearances, sizes, colours, location and shapes of haemorrhages; images from different clinical scenarios/aetiologies and images of different 'ages' (i.e. after a known number of days from first imaging). The individual images / haemorrhages were chosen from our database of over 100 children with accidental and abusive head injury and other encepthalopathies. The images and haemorrhages were chosen by the project co-ordinator who was not involved in the actual classification of the retinal haemorrhages. 
The RetCam images were downloaded onto a PC without any change to their format. Images were viewed on a 15" monitor - the same as those produced on the RetCam. High quality photographs were printed on Premium Glossy Photo Paper (A4 size). Haemorrhages were classified from the photographic images but observers had the opportunity to also view them from the PC screen.

Specified haemorrhages from each image, (generally 5 per fundal image) were classified by each examiner as a particular type (retinal layer haemorrhage) according to their current clinical understanding. Each colour retinal photograph was accompanied by a corresponding grey scale where the haemorrhages to be classified were numbered. Examiners ascribed the retinal haemorrhages to one of the following 8 retinal layer categories (vitreous, pre-retinal/subhyaloid, preretinal deep to the inner limiting membrane, intra-retinal (flame), intra-retinal (dot/blot), sub-retinal, schisis cavity, or indeterminate. Twenty-six retinal haemorrhages from 6 retinal photographs were represented to test intra-observer consistency. We have provided examples of three of these images,

\section{Figures 1-3.}

Examiners then conferred and agreed a common description for each haemorrhage (Table 1). By consensus, fewer (five) categories of haemorrhage were described (vitreous, pre-retinal, nerve fibre layer, intraretinal/subretinal, or indeterminate), and the study repeated using this agreed classification. Sample pictures of each different type of retinal haemorrhage as agreed by the examiners are shown in Figures 1, and 4-7.

Examples of 3 retinal photographs (Figures 1-3,) with matched colour and grey scale pictures are shown. In each case, the grey scale image shows numbered retinal haemorrhages (numbers 1-5) and the examiners were asked to classify the same haemorrhages on the corresponding colour image. Inter-observer agreement was measured for multiple observers using Fleiss' unweighted kappa statistic. Fleiss' unweighted kappa is a statistical measure for assessing the reliability of agreement between multiple observers when assigning categorical ratings to a number of items or classifying items.[14] Intra-observer agreement was measured using Cohen's unweighted kappa statistic.

These measures calculate the degree of agreement in classification over that which would be expected by chance, and are scored as a number between 0 and 1 . The generally accepted guidelines are that zero represents no agreement, 0.0-0.2 slight agreement, 0.21-0.4 fair agreement, 0.41-0.6 moderate agreement, 0.61-0.8 substantial agreement, and 0.81 - 1.0 almost perfect agreement, respectively.[15] We also compared the level of agreement between the two consultant 
paediatric ophthalmologists on the one hand and the two other clinicians on the other using a paired kappa statistic.

\section{RESULTS}

There was 'fair agreement' (Fleiss' unweighted kappa $=0.219$ ) on the initial classification of the 142 haemorrhages by all four examiners. One haemorrhage was classified as being in the vitreous by all 4 raters, but no other haemorrhage was identified as being in the vitreous by any examiner. By contrast, there was not 1 of the 142 haemorrhages that both consultant ophthalmologists concurred on as a sub-retinal haemorrhage, and given the little agreement between the 4 raters on sub-retinal haemorrhges, we deemed it best to include these in a combined category known as intra-retinal / subretinal in a new classification.

The examiners conferred and agreed a common retinal haemorrhage description with fewer (5) categories (Table 1) and the classification of the same 142 retinal haemorrhages was then repeated by all examiners. With this agreed classification there was slight improvement (Fleiss' unweighted kappa 0.356) but still 'fair agreement'. These results are shown in Table 2.

Now the category intra-retinal/subretinal shows the spread of agreement - three examiners agreed on 17 occasions and, two examiners on 30 occasions. In just over $50 \%$ of haemorrhages, all examiners agreed that they were not intraretinal / sub-retinal.

Over all retinal haemorrhages classified, there was perfect agreement between the 4 observers in $43 / 142(30 \%)$ of the haemorrhages.

Intra-observer agreement initially ranged from 'slight agreement' $(0.086)$, through 0.61 , to 0.783 i.e. substantial intra-examiner agreement, but on re-testing with the new classification, intra-observer agreement improved in all but one observer.

We also compared the pairs of examiners, in particular how the consultant ophthalmologists and 2 other clinicians performed. The paired kappa scores for the two consultant ophthalmologists initially was 0.2293 improving to 0.2977 with the new classification - "fair" agreement on both occasions. The improved Fleiss' agreement between 4 observers with the new classification was largely due to the other clinician's (not consultant ophthalmologists) improvement in inter-observer consistency. Table 3

\section{DISCUSSION}

Retinal haemorrhages in children are frequently associated with head injury, and in particular abusive head injury. In abusive head injury, haemorrhages are described by their number, [2,6] distribution and 
type or layer within the retina.[2,3] This paper does not assess the inter-rater agreement on recognising whether retinal haemorrhages are present or not, nor their size or extent, or their location, but rather how the appearance of the retinal haemorrhage accords with their perception of the defining features of retinal haemorrhages in different retinal layers.

There are however no currently universally accepted descriptions of childhood retinal haemorrhages. It is possible that any classification of retinal haemorrhages in children has the potential to be influenced by the presumed diagnosis and in order to eliminate any such bias, our study was designed so that the observers were masked to the aetiology of the retinal haemorrhages.

Retinal haemorrhages in children are generally classified according to shape and also colour. [1,2] Levin described nerve fibre layer haemorrhages as splinter or flame-shaped while deeper retinal haemorrhages are round or amorphous in shape and are called dot or blot.[2,3] Haemorrhages in deeper retinal layers are said to be darker in colour though this is not always a consistent feature. Hochman et al reviewed the literature on (adult) sub retinal haemorrhages and reported that they may vary in colour from bright red to dark red to green.[17]

Haemorrhages overlying major retinal blood vessels must be superficial, but no other definitive landmarks are available in the transparent retinal structures. Large haemorrhages lying just in front of the retina or within splits or schisis cavities of the superficial retinal layers are more easily identified histopathologically but even here there are inconsistencies between different published reports and between different methods of evaluation.[10-14,18] While it may be difficult to distinguish blood within a traumatic retinoschisis from preretinal or subhyaloid haemorrhage by appearance, it is claimed that they can be distinguished by the presence of circumlinear retinal folds that usually surround the retinoschisis cavities.[2,10,12] It is however uncertain that the presence of these folds automatically means that the associated haemorrhages always represent retinoschisis cavities or that the absence of folds indicates that they are not schisis cavities. In reported cases where clinical examination has been followed by post-mortem histopathological examination, there is frequently a significant discrepancy between the clinical diagnosis and the anatomical reality. Histopathological examinations in cases of childhood retinal folds have demonstrated haemorrhagic schisis beneath the internal limiting membrane, [10] subhyaloid haemorrhage,[10] and sub-retinal haemorrhage. [18]

We have demonstrated that a clinical classification of RetCam images of retinal haemorrhages in children, based on the generally held defining features of haemorrhages in different retinal layers, 
lacks consistency between examiners and even on re-examination by the same examiner. The agreement between observers using these generally-held clinical descriptions of retinal haemorrhages was 0.219 , but improved slightly after consensus definitions were created with fewer categories, comprising i. vitreous, ii. pre-retinal, iii. nerve fibre layer (flame \& diffuse), iv. intra-retinal (dot blot)/subretinal, or v. indeterminate (Fleiss' kappa $=0.356$ ). Similarly the intra-observer agreement for the 4 examiners generally improved after the authors' consensus definitions were used, (range 0.430 to 0.728$)$.

The Consultant ophthalmologists in this study showed a lack of consistent agreement. The wide variation in the appearances of the retinal haemorrhages, especially over time, means considerable difficulty in attributing a retinal layer to many of them. The consultants with their more extensive experience of viewing retinal haemorrhages are likely to appreciate the subtleties in these diverse appearances and adjust their classifications accordingly, subtleties that are not appreciated by other experienced non-ophthalmological consultants or non-consultant grade ophthalmologists.

The construction of a concise 5 point classification of retinal haemorrhages has appeared to be of assistance to the 'other clinicians' and their 'substantial' inter-rater consistency was responsible for nearly all of the improvement in the Fleiss kappa statistic for the multiple examiners and multiple categories between the two assessments.

From the above low kappa scores generally it can be seen that there is only 'fair' agreement amongst all clinicians in denoting a "layer" to the retinal haemorrhage appearance. Contributory factors to the relatively low levels of clinical agreement may be due to the variable quality of the retinal view or photographic image, which may be influenced by the degree of pupil dilatation, ambient lighting and/or illumination (if camera systems such as the hand-held RetCam or non-mydriatic cameras are used). The quality of the photographic images in our study, as in everyday clinical practice, varied.

Retinal haemorrhages after some days may assume a different appearance and not be like a typical textbook description. This may account for the limited inter-observer agreement. The raters were told the 'age' (days from admission to hospital) and their experience of the natural history of certain retinal layer haemorrhages (e.g. pre-retinal) could similarly have influenced the classification category chosen.

The low levels of agreement between observers reported here need to be seen in the context of similarly difficult areas of the clinical examination. Skalet et al compared remote grading of RetCam 
images in infants with retinopathy of prematurity to a gold standard clinical examination using indirect ophthalmoloscopy [19]. They found moderate agreement (Cohen's kappa 0.4-0.59) between remote observers for determining presence of "referral warranted-ROP" but poor agreement (kappa 0-0.19) for assessing vessel tortuosity. Wallace et al studied the agreement among paediatric ophthalmologists in diagnosing plus and pre-plus disease in ROP [20]. They reported frequent disagreement on the diagnosis of plus or pre-plus disease but did not quantify the degree of disagreement with kappa statistics.

Emanuele et al demonstrated variable interpretation of clinical examination versus stereo photographs in the grading of diabetic retinopathy (including "Fleiss" statistic).[21] However this referred only to the degree of disagreement between different grading techniques and not different observers using the same modality. Joshua et al reviewed the literature evidence about the accuracy and reliability of the physical examination and common clinical signs and reported a vast range of kappa values, particularly low for some aspects of the cardiac and respiratory examination.[22]

Retinal haemorrhage recognition is of paramount importance in abusive head injury, where haemorrhages of multiple layers are often described, but surprisingly without autopsy confirmation of retinal layer in most cases. Green et al [4] and Budenz et al [8] describe histopathological case series of infants who died from shaking injuries though neither provides any corresponding retinal images. Pierre-Khan et al on the other hand, reported the fundoscopic findings in suspected child abuse victims with subdural haematomas, and their group subdivided the retinal haemorrhages into retinal, retrohyaloid and vitreous haemorrhages but similarly with no corresponding post-mortem confirmation.[23] Mills described ten infants (3 died) with a mixture of pre-retinal haemorrhage and/or peripheral retinoschisis, without ocular pathology.[12] Most of the ophthalmic literature on ocular findings of shaking injuries in infants similarly report extensive multi-layer haemorrhages without precise pathological confirmation.

It is perhaps not surprising how difficult it is to achieve agreement on which layer of the retina the haemorrhages are in, by looking at the 'surface' only. Verification of the clinical/anatomical relationship will depend on future studies combining retinal images and ocular pathology or retinal images with 'depth' imaging, such as optical coherence tomography (OCT) or other techniques. Greenwald et al reported electroretinographic changes in infants with large posterior pole haemorrhages suggesting that a schisis had occurred with relative preservation of the photoreceptors (a-wave) but loss of the b- 
wave, due to supposed splitting of the retina.[11] Newer technologies such as OCT offer novel approaches to the evaluation of retinal haemorrhages in shaking injuries, although this is difficult to perform.[14] Sturm et al reported the OCT findings in three infants with shaking related eye injuries. Clinically, all three children had numerous bilateral, multilayered retinal haemorrhages and one had bilateral perimacular folds. The OCT however revealed vitreoretinal traction in all infants and a suspected haemorrhagic macular retinoschisis in one case. The morphology of the neurosensory retina close to retinal folds was severely disturbed and exact localization of schisis cavities was not possible.[14] While there is extensive evidence that haemorrhages occur throughout all layers of the retina as well as in front and beneath it in shaking injuries,[4-9] and while our study does not cast doubt on the recognition of the presence or absence of retinal haemorrhages, nor their location or extent, we suggest that it remains difficult to determine the precise layer of any retinal haemorrhage by clinical examination alone.

Our new classification (and attendant definitions) is a simple 5-point categorisation of retinal haemorrhages in different retinal layers with clear description and shows a marginal improvement in concordance between observers. Current understanding of what a retinal haemorrhage in different layers looks like and thus their classification, may partly be based on inferences from the appearance of retinal haemorrhages in adults, which are of a different aetiology and not a valid comparison. Maturational changes in the anatomy and function in the infant eye may account for some of the different appearances of the retinal haemorrhage in a particular retinal layer e.g. the retina vitreous interface is very different in infants compared to adults as demonstrated during vitrectomy surgery in infants.[24] Furthermore, retinal folds are frequently found in infants with retinal haemorrhages suggesting that vitreoretinal traction plays a greater role in haemorrhage formation in infants than in adults. $[10,12,14]$ It is possible that there may also be differences in the structure of blood vessel in infants rendering them more fragile than their adult counterparts, as has been demonstrated in the coronary arteries of newborns.[25]

While we suggest a shorter well defined classification of retinal haemorrhages in children can improve the agreement amongst clinicians, for categorising haemorrhages in a particular retinal layer, it may be more use for descriptions to emphasise the zonal location, number, size and appearance (shape and colour) of retinal haemorrhages, where a far greater level of inter-observer agreement would be achievable . [26] 


\section{Licence for Publication}

The Corresponding Author has the right to grant on behalf of all authors and does grant on behalf of all authors, an exclusive licence (or non exclusive for government employees) on a worldwide basis to the BMJ Publishing Group Ltd to permit this article (if accepted) to be published in BJO and any other BMJPGL products and sublicences such use and exploit all subsidiary rights, as set out in our licence (http://group.bmj.com/products/journals/instructions-for-authors/licence-forms).

\section{$\underline{\text { Competing Interest }}$}

Please list Competing Interests if they exist if not please include the following statement; Competing Interest: None declared. 


\section{Table1: Authors' classification of retinal haemorrhages}

$1 \quad$ Vitreous

may totally obscure view of fundus

mostly large

diffuse

(Figure 4)

2 Pre-retinal

large 'bag of blood'

dark red (usually, if viewed early post injury)

may be of different densities

may be a fluid level

"geographic" shapes

(Figure 1, black arrows)

3 Nerve fibre layer - flame (at same level as blood vessels)

radiate (follow the nerve fibres)

usually small and pink

- "diffuse"

(Figure 5)

appearance: large, pale pink map-like shape

(Figure 1, haemorrhage 1 / white arrows)

$4 \quad$ Intra-retinal includes - dot-blot

mostly circular, discrete

blood vessels in front of haemorrhage

(Figure 6)

- "Sub Retinal"

darker

blood vessels in front of haemorrhage

(Figure 7)

$5 \quad$ Indeterminate 
Table 2: Agreement between examiners on haemorrhages in specific retinal layers based on a 5 category classification: Occasions on which examiners labelled haemorrhages in each category.

\begin{tabular}{|c|c|c|c|c|c|}
\hline & \multicolumn{5}{|c|}{ Number of occasions in which examiners classified a haemorrhage by specific layer } \\
\hline $\begin{array}{l}\text { Number of } \\
\text { examiners }\end{array}$ & Vitreous & $\begin{array}{l}\text { Pre- } \\
\text { retinal/sub- } \\
\text { hyaloid }\end{array}$ & $\begin{array}{l}\text { Nerve fibre } \\
\text { layer }\end{array}$ & $\begin{array}{l}\text { Intra-retinal/sub } \\
\text { retinal }\end{array}$ & $\begin{array}{l}\text { Layer } \\
\text { indeterminate }\end{array}$ \\
\hline None & 141 & 37 & 67 & 74 & 125 \\
\hline $\mathbf{1}$ & 0 & 47 & 15 & 21 & 14 \\
\hline $\mathbf{2}$ & 0 & 33 & 13 & 30 & 3 \\
\hline $\mathbf{3}$ & 0 & 9 & 21 & 17 & 0 \\
\hline $\mathbf{4}$ & 1 & 16 & 26 & 0 & $\mathbf{1 4 2}$ \\
\hline total & $\mathbf{1 4 2}$ & $\mathbf{1 4 2}$ & $\mathbf{1 4 2}$ & $\mathbf{1 4 2}$ & \\
\hline
\end{tabular}


Table 3: Paired un-weighted kappa results comparing agreement between pairs of observers.

\begin{tabular}{|l|l|l|l|}
\hline & 8 category classification & $\begin{array}{l}\text { New 5 category } \\
\text { classification }\end{array}$ & Level of agreement \\
\hline $\begin{array}{l}\text { Ophthalmology } \\
\text { Consultants }\end{array}$ & 0.2293 & 0.2977 & No change / fair agreement \\
\hline $\begin{array}{l}\text { Other clinician } \\
\text { pair }\end{array}$ & 0.3568 & 0.6156 & $\begin{array}{l}\text { From fair to substantial } \\
\text { agreement }\end{array}$ \\
\hline
\end{tabular}




\section{References:}

1. Levin AV. Retinal haemorrhages and child abuse. In: David TJ, (ed). Recent advances in pediatrics, no. 18. London: Churchill Livingstone, 2000;151-219.

2. Levin A. Ocular manifestations of child abuse. Ophthalmol Clin North Am 1990;3:249-64.

3. Kaur B, Taylor D. Fundus haemorrhages in infancy. Surv Ophthalmol 1992;37(1):1-17.

4. Green MA, Lieberman G, Milroy CM et al MA. Ocular and cerebral trauma in non-accidental injury in infancy: underlying mechanisms and implications for paediatric practice. Br J Ophthalmol 1996;80:282-87

5. Morad Y, Kim YM, Armstrong DC et al. Correlation between retinal abnormalities and intracranial abnormalities in the shaken baby syndrome. Am J Ophthalmol 2002;134(3):354-9.

6. Wygnanski-Jaffe T, Levin AV, Smith $\mathrm{C}$ et al. Post-mortem orbital findings in shaken baby syndrome. Am J Ophthalmol 2006;142(2):234-40.

7. Betz P, Puschel K, Miltner E et al. Morphometrical analysis of retinal haemorrhages in the shaken baby syndrome. Forensic Sci Internat 1996;78:71-80.

8. Budenz DL, Farber MG, Mirchandani HG et al. Ocular and optic nerve haemorrhages in abused infants with intracranial injuries. Ophthalmologyl 1994;101:559-65.

9. Matschke J, Puschel K, Glatzel M. Ocular pathology in shaken baby syndrome and other forms of infantile non-accidental head injury. Int $J$ Legal Med 2008; Epub ahead of print.

10. Massicotte SJ, Folberg R, Torczynski E et al. Vitreoretinal traction and perimacular retinal folds in the eyes of deliberately traumatised children. Ophthalmology 1991;98:1124-27.

11. Greenwald MJ, Weiss A, Oesterle CS et al. Traumatic retinoschisis in battered babies. Ophthalmology 1986;93(5):618-24.

12. Mills M. Funduscopic lesions associated with mortality in shaken baby syndrome. J Am Assoc Pediatr Ophthalmol Strabismus 1998;2(2):67-71.

13. Weis A, Kodsi SR, Rubin SE et al. Sub retinal hemorrhage masquerading as a hemorrhagic choroidal detachment in a case of nonaccidental trauma. J Am Assoc Pediatr Ophthalmol Strabismus 2007;11(6):616-7.

14. Sturm V, Landau K, Menke M. Optical coherence tomography findings in shaken baby syndrome. Am J Ophthalmol 2008;146(3):363-68.

15. Fleiss JL. Measuring nominal scale agreement among many raters. Psychological Bulletin 1971;76(5):378-382.

16. Hochman MA, Seery CM, Zarbin MA. Pathophysiology and management of sub retinal hemorrhage. Arch Ophthalmol 1997;42(3):195-213.

17. Landis JR, Koch GG. The measurement of observer agreement for categorical data. Biometrics 1977;33:159-74.

18. Hochman MA, Seery CM, Zarbin MA. Pathophysiology and management of sub retinal hemorrhage. Arch Ophthalmol 1997;42(3):195-213.

19. Skalet AH, Quinn GE, Ying GS et al. Telemedicine screening for retinopathy of prematurity in developing countries using digital retinal images: a feasibility project. J Am Assoc Pediatr Ophthalmol Strabismus 2008;12(3)252-8.

20. Wallace DK, Quinn GE, Freedman SF, Chiang MF. Agreement among pediatric ophthalmologists in diagnosing plus and pre-plus disease in retinopathy of prematurity. J Am Assoc Pediatr Ophthalmol Strabismus 2008;12(4):352-6.

21. Emanuele N, Klein R, Moritz T et al. Comparison of dilated fundus examinations with seven-field stereo fundus photographs in the Veterans Affairs Diabetes Trial. J Dia Comp 2009;23:323-9.

22. Joshua AM, Celermajer DS, Stockler MR. Beauty is in the eye of the examiner: reaching agreement about physical signs and their value. Int Med J 2005;35:178-187.

23. Pierre-Khan V, Roche $O$, Dureau $P$ et al. Ophthalmologic findings in suspected child abuse victims with subdural haematomas. Ophthalmology 2003;110(9):1718-23.

24. Joshi MM, Ciaccia S, Trese MT et al. Posterior hyaloid contracture in pediatric vitreoretinopathies. Retina 2006 Sep;26(7 Suppl):S38-41.

25. Kurosawa S, Kurosawa H, Becker AE. The coronary arterioles in newborns, infants and children. A morphometric study of normal hearts and hearts with aortic atresia and complete transposition. Int J Cardiol 1986;10(1):43-56.

26. Fleck BW, Tandon A, Jones PA et al. An inter-rater reliability study of a new "zonal" classification for reporting the location of retinal haemorrhages in childhood for clinical, legal and research purposes. Br J Ophthalmol, epub ahead of print, Oct 2009. 


\section{Figure Legends:}

Figure 1: Colour retinal image of left eye with matched grey scale image of a 13 week old boy with non-accidental head injury, within 24 hours of admission.

Figure 1 (left) also gives examples of 'pre-retinal haemorrhages' (indicated by black arrows) and also a large pale diffuse, map-like nerve fibre layer haemorrhage (white arrows) as identified by the number 1 on the matching grey image.

Figure 2: Colour retinal image of left eye with matched grey scale image of same infant as Figure 1, on day 26 after admission.

Figure 3: Colour retinal image of left eye with matched grey scale image of a 10 year old boy with confirmed accidental head injury, within 24 hours of admission.

Figure 4: Example of a vitreous haemorrhage.

Figure 5: Small flame shaped nerve fibre layer haemorrhages (two indicated with black arrows), seen in left eye of an 8 month old very dark skinned child, with non-accidental head injury.

Figure 6: Multiple dot-blot intra-retinal haemorrhages (some indicated with arrows) seen in the left eye of a 7 week old child with non-accidental head injury (image on day 3 after admission).

Figure 7: Example of a sub-retinal haemorrhage (black arrow). 


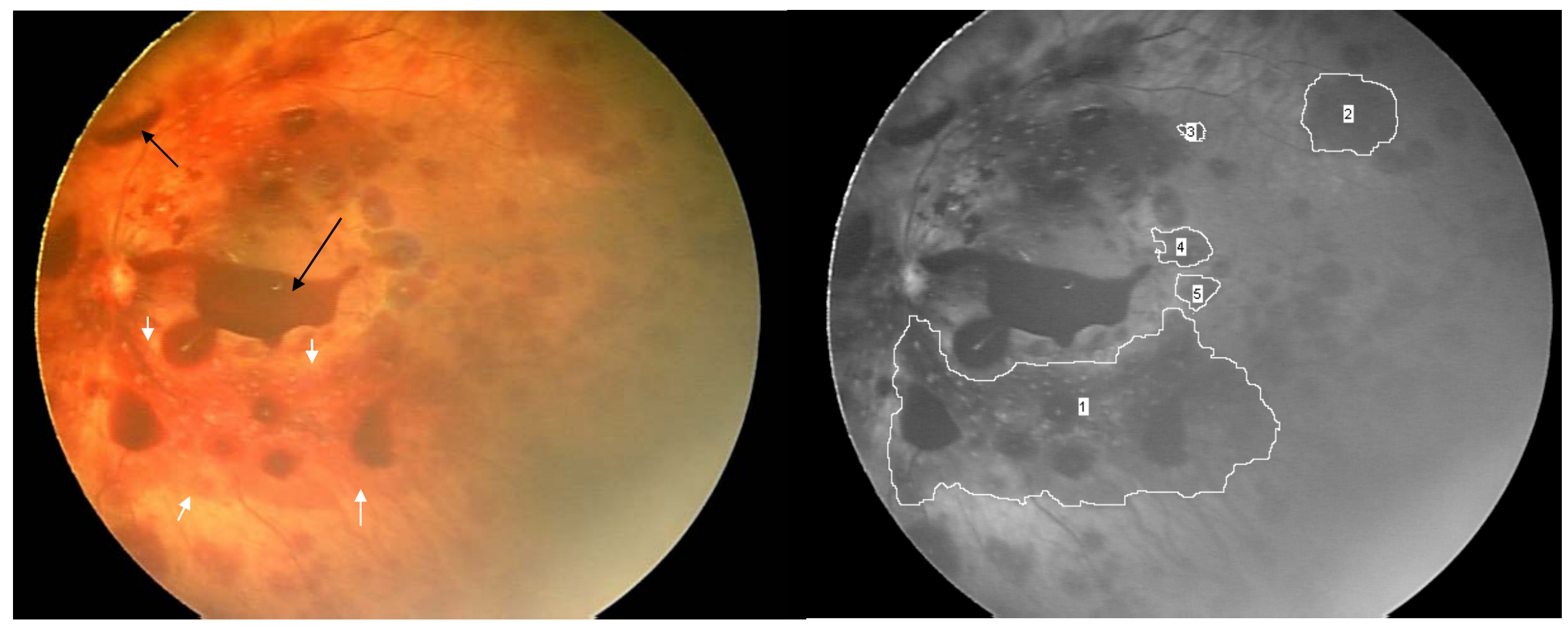




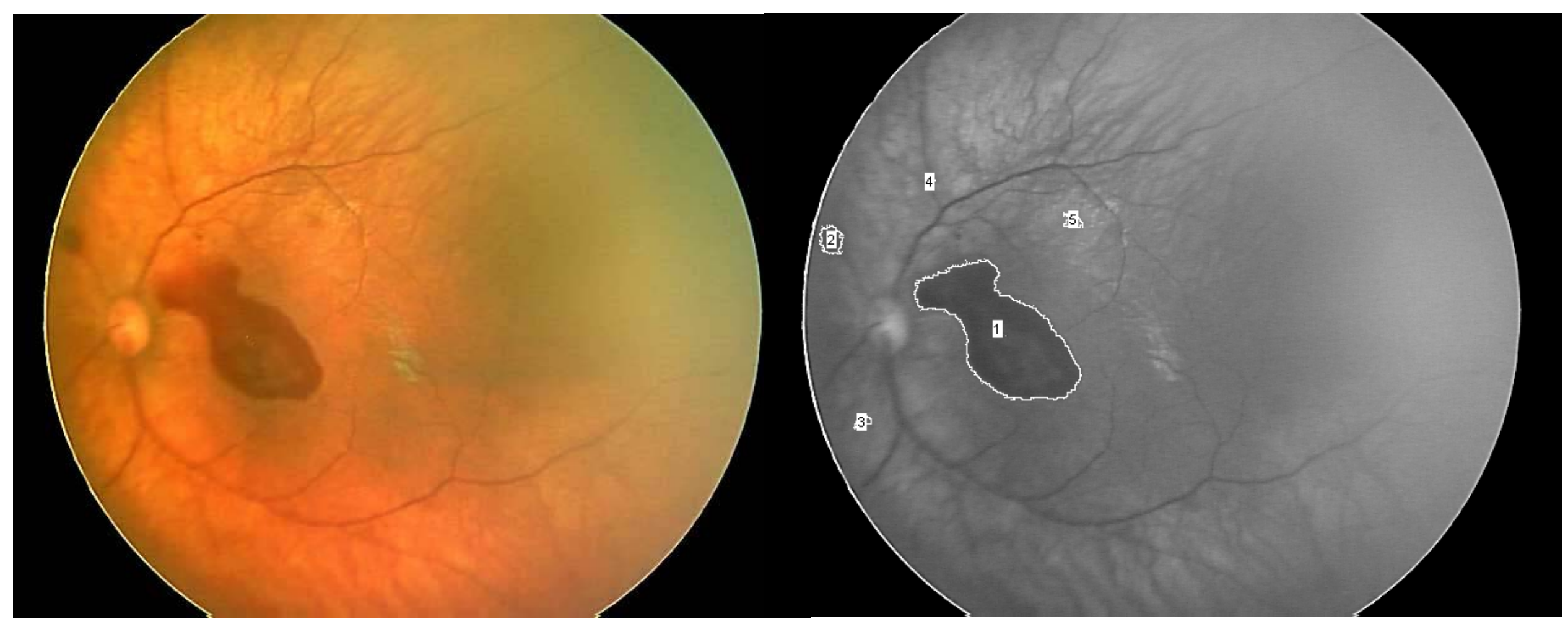




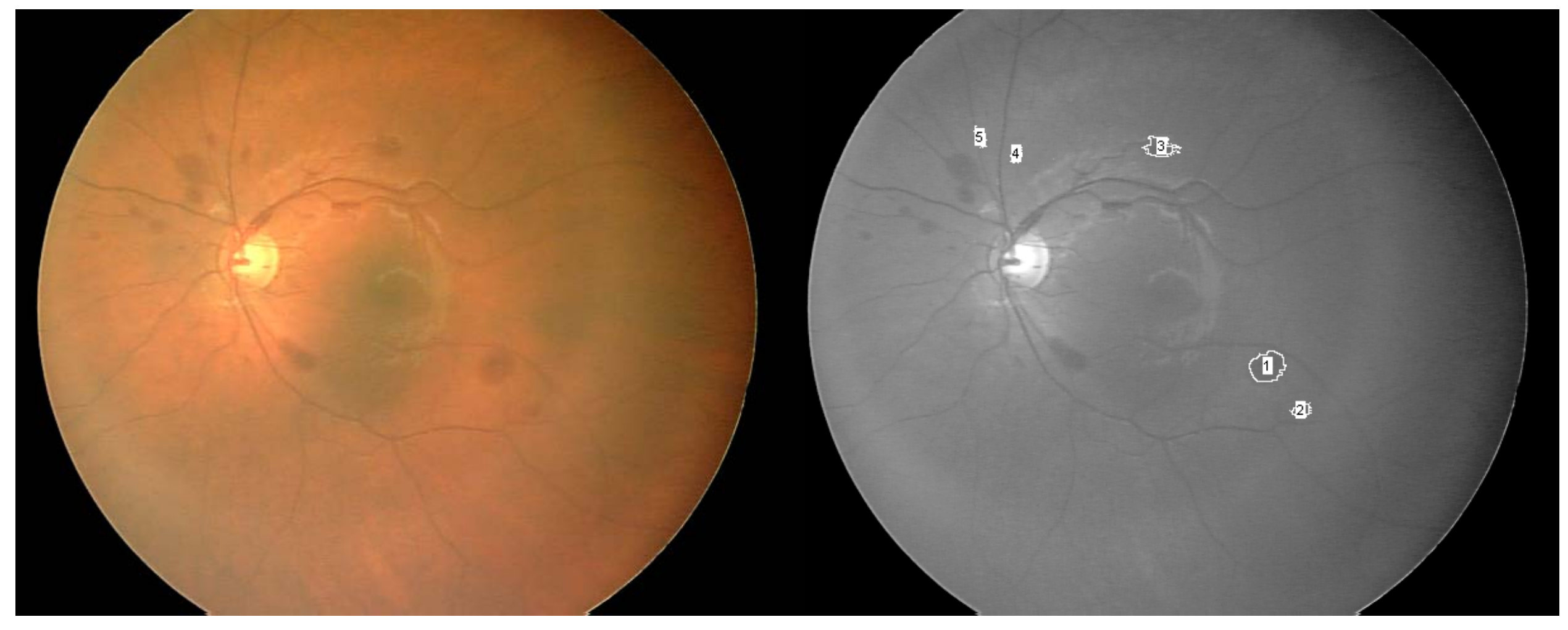




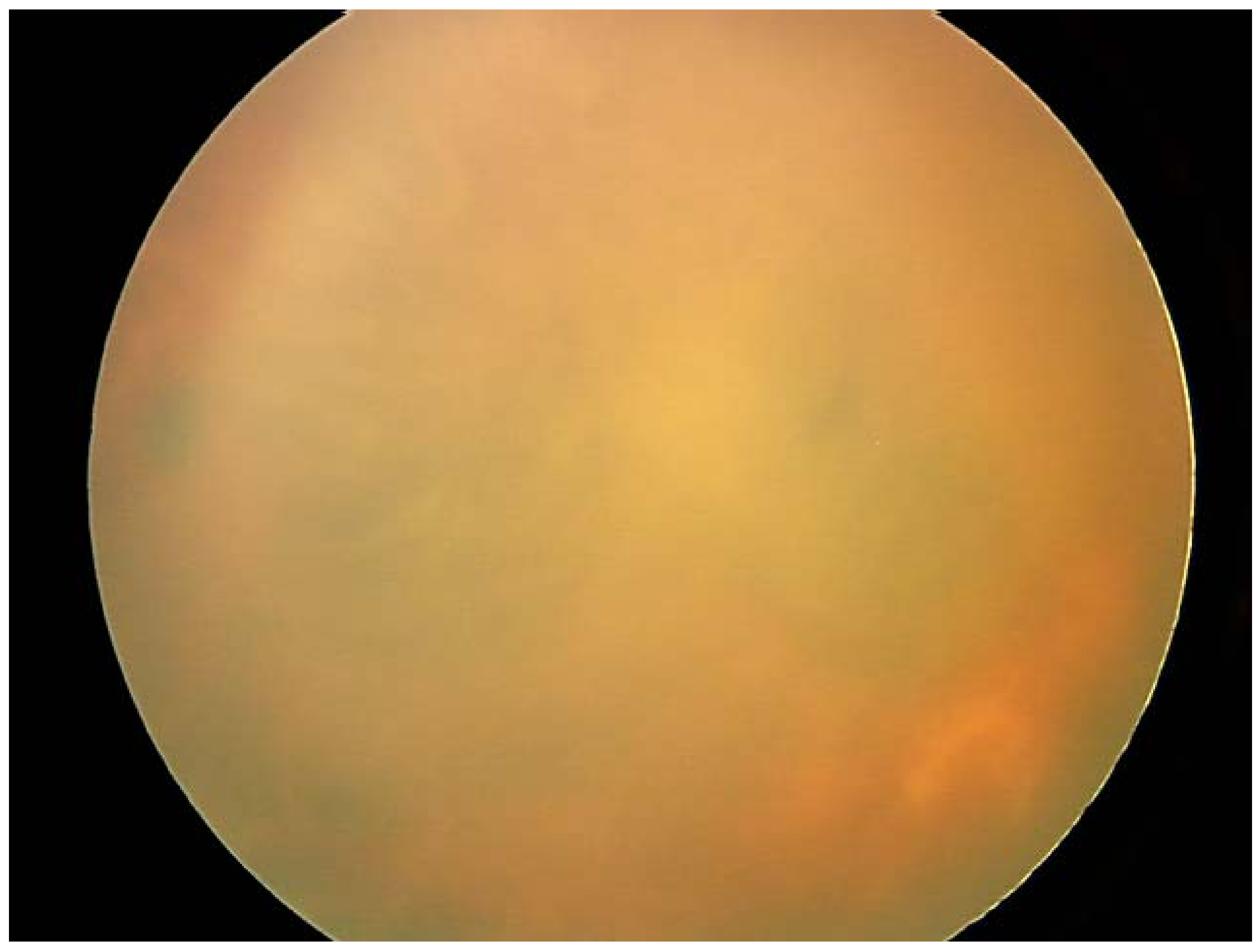




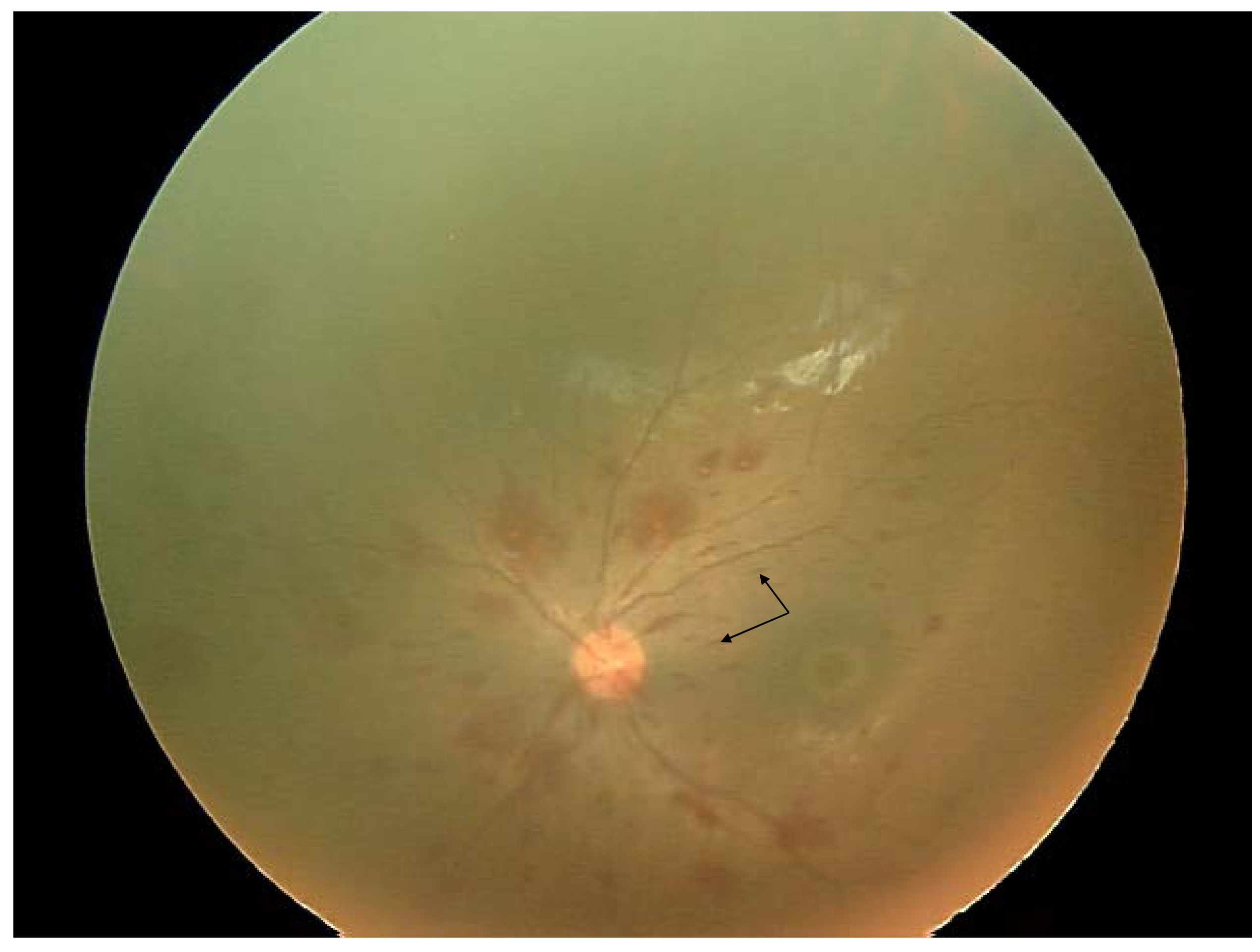




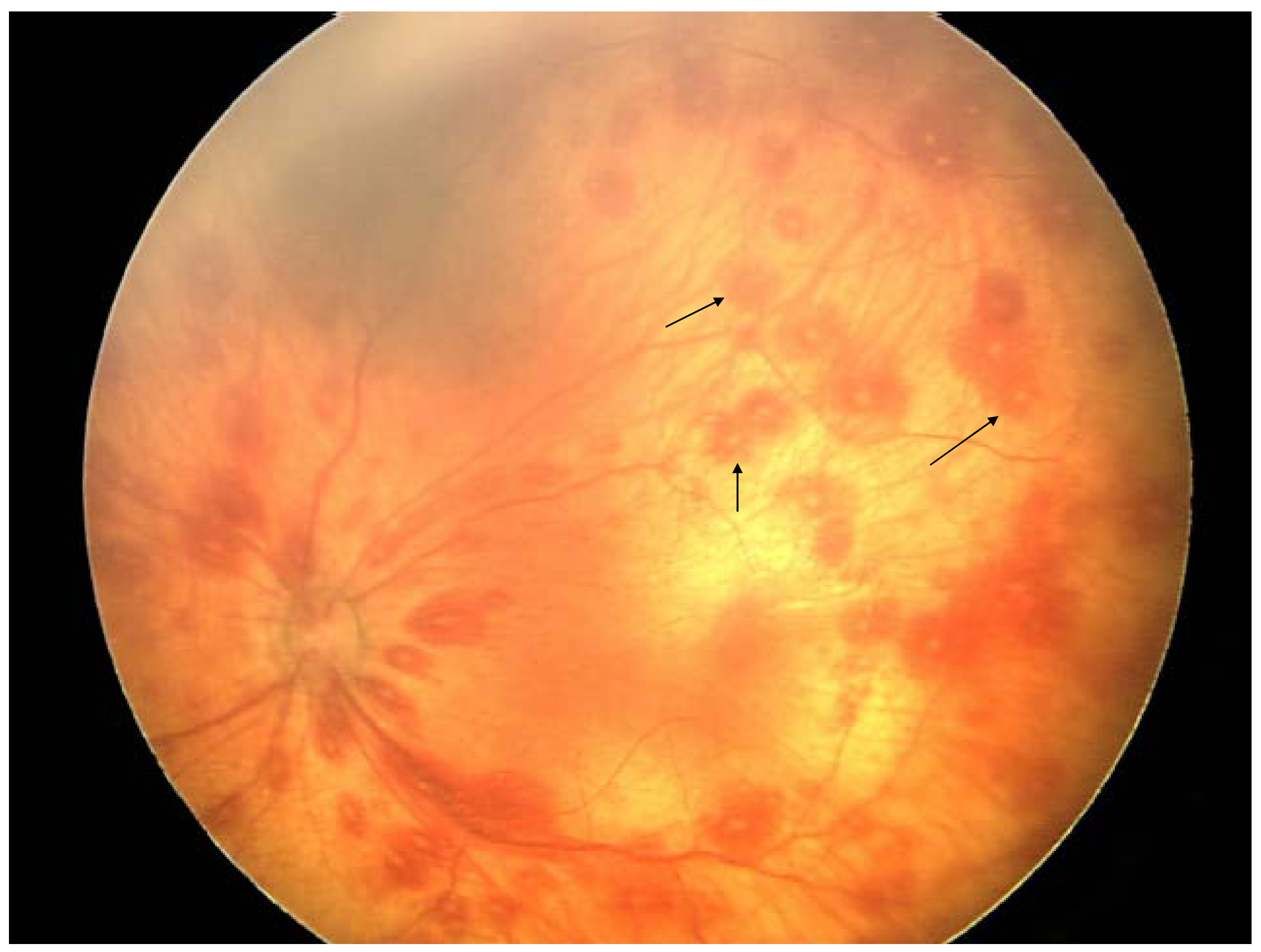




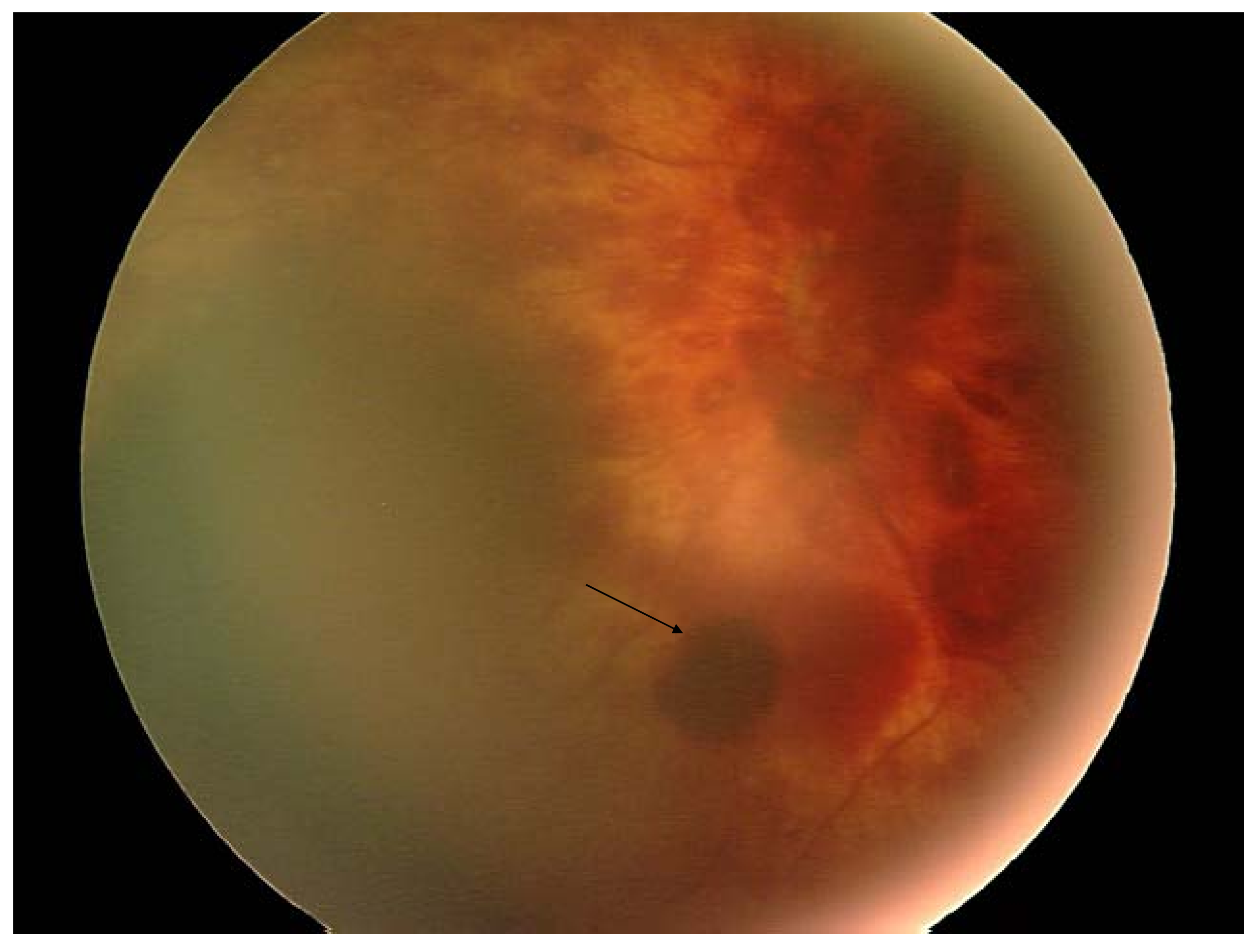

